\title{
Understanding and predicting large-scale hydrological variability in a changing environment
}

\author{
Nicolas Massei $^{1}$, Daniel G. Kingston ${ }^{2}$, David M. Hannah ${ }^{3}$, Jean-Philippe Vidal ${ }^{4}$, Bastien Dieppois ${ }^{3,5,6}$, \\ Manuel Fossa ${ }^{1}$, Andreas Hartmann ${ }^{7}$, David A. Lavers ${ }^{8}$, and Benoit Laignel ${ }^{1}$ \\ ${ }^{1}$ Normandie Univ, UNIROUEN, UNICAEN, CNRS, M2C, 76000 Rouen, France \\ ${ }^{2}$ Department of Geography, University of Otago, Dunedin, New Zealand \\ ${ }^{3}$ School of Geography, Earth \& Environmental Sciences, University of Birmingham, \\ Edgbaston, Birmingham, B15 2TT, UK \\ ${ }^{4}$ INRAE, UR RiverLy, Centre de Lyon-Grenoble, 69625 Villeurbanne, France \\ ${ }^{5}$ Centre for Agroecology, Water and Resilience (CAWR), Coventry University, \\ Ryton-on-Dunsmore, Coventry, CV8 3LG, UK \\ ${ }^{6}$ Department of Oceanography, University of Cape Town, Private Bag X3, \\ Rondebosch, 7701, Republic of South Africa \\ ${ }^{7}$ Chair of Hydrological Modeling and Water Resources, Freiburg University, Freiburg, Germany \\ ${ }^{8}$ European Centre for Medium-Range Weather Forecasts (ECMWF), Shinfield Park, Reading, RG2 9AX, UK
}

Correspondence: Nicolas Massei (nicolas.massei@univ-rouen.fr)

Published: 16 September 2020

\begin{abstract}
In a context of climate, environmental, ecological and socio-economical changes, understanding and predicting the response of hydrological systems on regional to global spatial scales, and on infra-seasonal to multidecadal time-scales, are major topics that must be considered to tackle the challenge of water resource management sustainability. In this context, a number of strongly-linked key issues need to be addressed by the scientific community, including: (i) identifying climate drivers of hydrological variations, (ii) understanding the multi-frequency characteristics of hydroclimate variability, including evolution of extremes (meteorologi$\mathrm{cal} /$ hydrological event scale to long-term natural/internal climate- or anthropogenic-driven variations and trends), (iii) assessing the influence of local- to regional-scale basin properties on hydrological system response to climate variability and change, (iv) identifying the evolving contribution of anthropogenic water use in observed hydrological variations. Based on pan-European collaborations, activities of the EURO-FRIEND "Large-scale variations in hydrological characteristics" group aim at generating new findings to improve our understanding of hydrological systems behavior sensu lato (i.e. surface and sub-surface) on large spatial and temporal scales (i.e continental - multidecadal). Through selected examples, this contribution emphasizes recent research developments in characterizing and modeling of climate-hydrology linkages at different temporal and spatial scales, as well as recent insights on climate-hydrology scaling characteristics (i.e. long-term persistence, dependance of processes, of hydrological behaviors, of large-scale climate/hydrology linkages on time-/spatial scales), longterm hydrometeorological reconstructions, and large-scale hydrological model refinement taking into account spatial heterogeneity of watershed physical characteristics.
\end{abstract}




\section{Introduction}

Understanding, characterizing and predicting changes in hydroclimatic conditions on land are essential to optimize water use and mitigate the impact of climate and environmental changes on water resources and related hazards (e.g. floods, droughts, erosive events, degradation of water quality, hydropower...). One of the main problems in predicting longterm hydroclimate variability is related to the limitations of climate models to adequately simulate internal modes of variability, whose impacts can sometimes worsen, sometimes attenuate the impact of climate change on regional hydrological systems, especially at decadal scales (Hawkins and Sutton, 2009; Deser et al., 2012, 2014; Roberts et al., 2015). For instance, natural phenomena such as the Interdecadal Pacific Oscillation and the Atlantic Multidecadal Oscillation substantially modify the rate of warming in many regions of the globe (Zhang et al., 2007; Meehl et al., 2016; Deser et al., 2012). It is then important to distinguish between trends and low-frequency variability inherited from climate system dynamics. Impacts usually affect large regional to continental spatial scales and highly depend on local physiographic conditions such as basin characteristics and land-use.

A number of key issues need to be addressed by the scientific community in order to understand and predict the large-scale hydrological response to climate variability and environmental changes, and to tackle the major challenge of adapting water resource management to climate change. This paper presents a reflexion on characterization, forcing factors, methodological approaches to hydrological variability, partly based on recent research of EURO-FRIEND Water Projet 3 "Large-scale variations in hydrological characteristics" members. It mainly focuses on the following particular points: (i) identification of the climate drivers of hydrological variations and changes, (ii) characterization of hydrological variability across time-scales, (iii) influence of basin characteristics on hydrological responses to climate variability and changes, (iv) the need for long-term (palaeo-)hydrological/climatic reconstructions to help understanding recent hydroclimatic variability and trends.

\section{Identifying the climatic drivers of large-scale hydrology}

Establishing links between hydrological variability and large-scale climate is crucial to understand how hydrology responds to climate changes and eventually to predict hydrological variations and develop climate-impact scenarios. Different complementary approaches can be undertaken. Some of them focus on describing statistical relationships between parts of the climate system and land surface water. However, understanding climate/hydrology links requires deeper analysis of mechanisms at play for developing a coherent and comprehensive understanding about how water flows from the ocean, through the atmosphere, to the land surface.

\subsection{Atmospheric circulation-based analyses}

At their most general and wide-ranging, studies of the role of atmospheric circulation as a control on large-scale hydrological variation involve correlation of hydrological metrics with gridded geopotential height data (e.g. Kingston et al., 2015). Alternatively, composite analysis of such gridded data sets may be used, based on a threshold of high or low values for some aspect of hydrological variation (e.g. river flow - Kingston et al., 2016a; precipitation - Lavers et al., 2013 and Massei et al., 2017). Such studies often focus on defined modes of coupled ocean-atmospheric circulation variation, such as the Atlantic Multidecadal Oscillation (AMO), North Atlantic Oscillation (NAO) and El Nino Southern Oscillation (ENSO), and at monthly or seasonal . At such spatial and temporal scales, the relatively high temporal and spatial autocorrelation of sea-surface temperatures (SSTs) can make this variable a particularly important focus for understanding large-scale variation in hydrological processes (e.g. Ionita et al., 2017; Kingston et al., 2015).

Rather than focusing on hemispheric or continental scale ocean-atmosphere variations, other studies of climate control on hydrological variation examine more closely the atmospheric circulation co-located with the immediate hydrological study. These typically make use of synoptic-scale weather classifications, such as the Lamb Weather Types (UK; Lamb, 1972), Kidson Weather Types (New Zealand; Kidson, 2000), or the European-scale Grosswetterlagen (James, 2007). Such classification schemes are typically calculated at daily or subdaily scale, often making them suited to event-scale analyses (e.g. Fleig et al., 2011, in addition to longer-term characterization of the atmospheric circulation - land surface hydrology connections. Multi-scale analyses may also investigate relationships from SSTs to large-scale atmospheric circulation patterns and subsequently synoptic weather types (Hannah et al., 2014).

\subsection{Atmospheric pathways to precipitation delivery}

Analyses of large-scale geopotential height and wind fields can provide strong indications of delivery of warm/cold/wet/dry air-masses over a region based on corresponding changes in pressure gradient, orientation and presence of high and low pressure systems. However, such analyses do not ultimately provide quantitative evidence of changes in hydrologically relevant variables (i.e. precipitation supply). One approach to help filling the gap from largescale atmospheric circulation to airmass/precipitation supply is to analyze more specifically the source and trajectory of air-masses through the atmosphere using reanalysis or climate model data. One method by which such an approach can be achieved is back trajectory analysis, whereby parcels of air spatially and temporally coincident with a hydrologically significant event (i.e. extreme precipitation, snowmelt or evaporation) are tracked backwards in time. The back- 
wards trajectory thus reveals how parcels of air reach the hydrologically significant event and interact with larger-scale weather types and/or circulation patterns (e.g. Kingston and McMecking, 2015; Sahin et al., 2015). Alternatively to tracking the physical trajectory of air parcels, the geochemical characteristics of precipitation delivered to the land surface can also provide information on air-mass characteristics, precipitation source and moisture recycling from the surface to the atmosphere (e.g. Fiorella et al., 2018; Bass et al., 2014).

\subsection{Moisture transport mechanisms: blocking, storm tracks and atmospheric rivers}

A further means to provide more detail information on connections from large-scale circulation to land-surface hydrology is to focus on the role of specific atmospheric phenomena for delivering moist/dry/warm/cold air masses, particularly in relation to precipitation occurrence. For example, atmospheric blocking events are often associated with low precipitation totals, and outside of winter, with above average temperatures - such as during the 2015 summer drought in Europe (Ionita et al., 2017). Similarly, the presence of blocking typically results in diversion of prevailing winds and thus storm tracks - as was also observed during the 2015 European drought (Ionita et al., 2017). The relatively recent increased attention given to the role of atmospheric rivers (extremely intense and narrow "rivers" of atmospheric water vapour flux) has also led to new understanding of the processes leading to extreme rainfall and flooding events: for individual rivers (e.g. Lavers et al., 2015), regions, and globally (e.g. Kingston et al., 2016b; Lavers and Villarini, 2013; Paltan et al., 2017). Similarly, the absence of such features has been linked to drier than normal conditions, including drought (Paltan et al., 2017).

\subsection{Hydrological prediction}

Identification of concurrent climate-hydrology relationships such as those described in previous section provides important information on the series of processes that connect the climate system variation to large-scale hydrological variation. Whilst a critical step in developing understanding of the drivers of hydrology and in turn water resources, substantial additional benefit (particularly from an applied perspective) comes from the identification of lag-lead relationships in the ocean-atmosphere-land surface system, and so the potential for improved predictability of water resource availability. Seasonal lag-lead relationships typically focus on the role of slowly-varying components of the climate system, particularly SSTs (e.g. Kingston et al., 2013; Ionita et al., 2017), whereas on daily to weekly scales it has recently been shown that by focussing on water vapour transport instead of directly on precipitation has the potential to increase the forecast horizon by up to three days (Lavers et al., 2014).

\section{Hydrological variability across time-scales}

Understanding the long-term evolution of hydrological variations has been the subject of a large number of studies in recent decades (Hannaford et al., 2013; McCabe and Wolock, 2002; Pagano and Garen, 2005; Stahl et al., 2010). Most of them focused on the identification of trends in hydrological processes (precipitation, temperature, streamflow). However, characterization of high- to low-frequency hydrological variability, beyond trend identification only, now appears necessary for understanding the evolution and forcing factors of hydrological phenomena in a changing climate. In this framework, identifying intrinsic oscillations affecting both large-scale climate and hydrological variables over multiple time-scales provides new insights.

\subsection{Trends and low-frequency variability}

Assessing the low-frequency variability of hydrological and hydroclimatic variables received increasing attention for the past years. On the pan-European scale, for instance, Gudmusson et al. (2011) or Hannaford et al. (2013) addressed this issue. Gudmusson et al. (2011) investigated the lowfrequency variability of runoff for 358 watersheds across Europe, and deduced that low-frequency behavior would follow well known continental-scale atmospheric features, whereas watershed properties would explain the proportion of variance of low-frequency fluctuations. Applying a so-called multi-temporal approach for trend analysis on a database comprising 132 european watersheds, Hannaford et al. (2013) highlighted that magnitude and direction of shortterm trends were strongly influenced by interdecadal variability. Investigating river flow variations at 38 gauging stations in metropolitan France, Boé and Habets (2014) highlighted the large amplitude of the multi-decadal variations in French rivers. Similarly, using 500 years observational and reconstructed hydroclimatic records, Dieppois et al. (2016) highlighted increasing multidecadal variability in the Seine river watershed, whose contribution is greater than the general trend to wetter conditions, since in the mid-19th century. Both studies emphasized on the importance of quantifying such variability, which may modify the long-term effect of global climate change on hydroclimatic processes (amplification, attenuation or sometimes inversion). This is also of crucial importance for short-length observational time-series and classical trend detection approaches, which can be substantially affected by potential interactions with decadal to multidecadal fluctuations. In this sense, it also constitutes a significant source of uncertainty for near-future climate projections, as multidecadal fluctuations are largely underestimated in current state-of-the art models (e.g. Ault et al., 2012, 2013) and contributing to uncertainties associated with internal climate variability (Keenlyside et al., 2008). 


\subsection{Time-frequency approaches for characterizing hydrological variability}

One consistent means in the aim of better characterizing lowfrequency variability and trends relies on the full exploration of the total range of the time-series spectrum. Since knowledge about time-evolution of hydroclimate variability is important, multi-frequency or multiresolution approaches need to be used, as proposed by Anctil and Coulibaly (2004), Coulibaly and Burn (2004), Labat (2006), or more recently by Massei et al. (2010, 2017), Massei and Fournier (2012), Kingston et al. (2016a) and Dieppois et al. (2013, 2016). These authors used continuous wavelet transform or multiresolution techniques (e.care of mostg. wavelet-based, empirical mode decomposition) to explore the time-frequency spectral content of precipitation, streamflow or climate indices in order to identify the different oscillatory components explaining the variance of such signals and its change through time. Kingston et al. (2016) used such techniques in addition to correlation analysis, partial least-square regression and composite analysis for understanding of the circulation-climate-inflow relationships for three headwater lakes in the Waitaki basin (New-Zealand). The approach allowed them to demonstrate, not only the presence of statistical relationships, but also their temporal location and periodicity together with an identification of underlying physical mechanisms. Studying precipitation and streamflow on the Seine river watershed in France between 1950 and 2008, Massei et al. (2010, 2017) and Massei and Fournier (2012) found interannual ( $\sim 7$-years) and interdecadal ( $\sim 17$-years) oscillations, whose fluctuations are only significant, respectively, since the 1970s and 1990s, that would explain $23 \%$ of daily Seine streamflow, and up to $35 \%$ of daily deseasonalized flow. Using similar methodology, Dieppois et al. (2016) also identified multi-decadal fluctuations ( $\sim 64$ years) in the Seine river watershed, whose contributions significantly increase in the mid-19th century. Compared to low-pass filtering, spectral or multiresolution-based approaches allow for separating and extracting components from high-to lowfrequencies, making it possible (i) to analyze separately the time evolution and the variability of all statistically significant frequency components, (ii) to look for possible different determinism associated to these components.

\subsection{Linking large-scale climate and hydrology across temporal scales}

As internal modes of climate variability and associated teleconnections oscillate over a number of different time-scales, so do hydrological variables, on regional or even local scales (e.g. at weather stations or small watershed outlets). This leads to a number of key-questions: do large-scale climate and local-scale variations co-vary similarly for all timescales? Can we identify statistical and/or physical links between large- and local-scale variables that would be hidden when accounting for linear or nonlinear correlation analysis only? Can we define processes that are associated to characteristic oscillations? Which processes become eventually filtered out by local characteristics?

In northern France, Massei et al. $(2007,2010)$ and Massei and Fournier (2012) identified clear co-variation between the NAO index, precipitation and discharge in the Seine river watershed at specific time-scales: interannual ( $\sim 7$-years) and interdecadal ( 17-years). Dieppois et al. $(2013,2016)$ then proposed that interdecadal to multidecadal hydroclimatic fluctuations in the Seine river watershed were associated with a south-eastward (southwestward) shift of the Icelandic Low (Azores High), which is particularly pronounced in Spring. This interdecadal shift in the NAO center action was consistent with Fritier et al. (2012), who showed that $\sim 17$ years interdecadal fluctuations were significantly detected in the Icelandic low, only. According to Hilmer and Jung (2000), anomalous sea-ice and fresh through Fram Strait could have helped to drive such an eastward shift in the Icelandic Low over the recent decades, and at the interdecadal time-scale. Similar interactions between Arctic sea-ice, which would be linked to the AMO, could also occur at the multidecadal time-scale, as suggested by the recent work of Miles et al. (2014). In addition, combining composite/correlation analysis and multiresolution filtering technics, Massei et al. (2017) show that atmospheric patterns linked to rainfall and streamflow in the Seine river watershed, where progressively shifting from local/regional convective atmospheric patterns (i.e. rainfall associated with low-pressure system centered on the watershed) to largescale zonal circulations (i.e. NAO-like patterns) from intraseasonal ( $\sim 3$ months) to interdecadal ( $\sim 17$ years) timescales. While previous studies suggested climate-streamflow predictions were using raw data (e.g. Lavers et al., 2013), Massei et al. (2017) highlighted that prediction skills could thus be substantially improved by tracking the predictor at the different time-scales.

\section{Research issues deserving increasing attention: assessing the role of large-scale basin characteristics and bridging the gap between historical period and palaeo-hydroclimatic time-scales}

Amongst many scientific questions that still need to be addressed in the field of large-scale hydrology, investigating the role of basin properties on hydrological variability and the need for long-term hydrological reconstructions in particular constitute important issues to which more efforts should be focused. On the one hand, it appears crucial to gain new insights into understanding physical processes at play in watersheds, including for instance recharge processes or surface water/ground water interactions. In particular, improving upscaling procedures would be needed, that would allow for a 
more realistic consideration of local-scale processes in largescale hydrological models. On the other hand, the need for a better understanding and more comprehensive characterization of long-term variability in a context of climate change requires "zooming out" hydrological time series; looking back at the past may constitute one important means to assess the significance of observed trends and low-frequency variations, and to disentangle natural and anthropogenic hydroclimatic variations.

\subsection{The influence of basin characteristics on hydrological response to climate variability and change}

Assessing the relationships between large-scale climate and hydrological variations from the watershed scale up to the regional or even continental scale very often involves comparison between hydrological output variations, e.g. streamflow (Kingston et al., 2006; Lavers et al., 2013; Massei et al., 2010), low-flow characteristics (Giuntoli et al., 2013), ground water level (Holman et al., 2011; El Janyani et al., 2012; Lavers et al., 2015) and large-scale atmospheric variables or circulation indices.

Most of these authors, however, highlighted the need for a better understanding of basins properties in order (i) to gain new insights into the large-scale climate and local-scale hydrological relationships, (ii) to improve projections of water resources availability under climate change.

This conclusion was reached for instance by Laizé and Hannah (2010), who attempted to assess the respective roles of large-scale atmospheric circulation, regional climate and basin properties on streamflow based on a database comprising 104 gaging stations in Great Britain. They underlined the important, but variable role of basin properties in modifying climate signals in river flow and the need to consider both sets of controls in evaluating hydrological sensitivity to climate change.

Basin properties operate different types of filtering of large-scale climate fluctuations according to time-scale. For shorter time-scales, the basins transfer functions smooth out the climate input. Beyond a certain higher time-scale, the input signal is no longer frequency-modulated (i.e., the climate oscillations are recovered at the exact same frequency in the output). This is can be easily related to the conclusion drawn by Gudmusson et al. (2011) for instance, who noticed that the low-frequency behavior of streamflow on the panEuropean scale followed well known continental-scale atmospheric features, whereas watershed properties would explain the proportion of variance of such low-frequency fluctuations.

Since higher frequencies are being filtered out, the lowfrequency variations corresponding to long time-scales are clearly expressed and explain very often a non-negligible part of variance in output signals (Slimani et al., 2009). The role of aquifers in this process, acting as potentially strong low- pass filters, is pre-eminent, especially where low-flows are strongly sustained by ground water or in places where ground water flooding may occur.

El Janyani et al. (2012) attempted to relate the proportion of variance explained by frequency components in chalk ground water levels in northwestern France according to geological heterogeneity (thichness of 2 types of surficial formations, vadose zone and aquifer). These authors conducted cluster analyses based on the frequency content of the data and detected a similar interannual variability in ground water level and winter-months NAO. They finally interpreted of the geological forcing factors of piezometric variability using ANOVA to define explanatory variables. The authors concluded that the location of the piezometer along the flowpath, as well as the size of the ground water sub-basin considered were determinant in the structure of the frequency content of piezometric time-series: the more downstream the piezometer, the higher the amplitude of low-frequencies.

Thiéry et al. (2018) used the results, obtained at an experimental site in northern France, of a 2.5-year monitoring of water content, soil temperature, matrix pressure in the chalk aquifer under various natural or forced infiltration conditions, to develop a vertical numerical flow model as input to a ground water flow model. The refinement of the modeling approach based on improved knowledge on infiltration processes eventually allowed the ground water model to reproduce very well the interannual variability of ground water level, which had been related to large floods in northern France and southern England in winter and spring 20002001.

As pointed out by Hartmann et al. (2017), accounting for local to regional scale heterogeneity can actually reveal crucial for more consistent modeling of hydrological response to climate variability and change and appropriate water resources management. In their study on carbonate rock regions of Europe, Northern Africa, and the Middle East, these authors showed that accounting for carbonate heterogeneity (presence of karstic terranes) results in actual recharge rates up to four times larger for present conditions and up to five times larger for potential future conditions than estimated when recharge is considered homogeneous.

\subsection{Looking back at the past using hydrometeorological reconstructions}

The release of global extended reanalyses like 20CR (Compo et al., 2011), ERA20C (Poli et al., 2016) or CERA-20C (Laloyaux et al., 2018) over the past few years now provide reconstructions of global atmospheric circulation back to the 19th century onwards. It thus opened the way for deriving local-scale meteorological reconstructions and resulting catchment-scale hydrological reconstructions based on statistical downscaling methods and hydrological modeling tools (Dayon et al., 2015; Minvielle et al., 2015; Kuentz et al., 2015; Caillouet et al., 2016, 2017). These new high- 
resolution datasets thus now allow studying the climate variability at the local scale, as well as the resulting hydrological variability for small catchments. Long-term analyses of these datasets for example highlighted the large multidecadal variability in precipitation and streamflow over France over the last 140 years, a variability already suggested by hydrometric studies for specific catchments (Kuentz et al., 2014) or from sparse streamflow measurements over metropolitan France (Boé and Habets, 2014).

Hydrological and climatological reconstructions also constitute a unique means to tackle the challenge of estimating long-term statistical properties of climate variability beyond the time-scale of observational records. These approaches attempt to bridge the gap between hydrological/climatic observations and palaeo-hydrological/palaeo-climatic records, and received growing attention in the last recent years. Studies seek to link the statistical information beared by historical records and that contained in climatic or hydrological proxies in order to gain additionnal insights into interpretation of low-frequency variability and trends in hydrological processes (Dieppois et al., 2016; Iliopoulou et al., 2018; Markonis and Koutsoyiannis, 2016; Markonis et al., 2018). Characterizing long-term persistence, for instance, may reveal particularly relevant for improving hydro-climatic extreme models or understand observed hydrological variations under climate change (Markonis and Koutsoyiannis, 2016). The conclusions drawn from such studies may have important implications in terms of water management, including floods and droughts, for instance. Among recent palaeo-hydrological studies, Wilhelm et al. (2015) could reproduce the main regional hydrological trends (periods of high flood-frequency, ranges of flood-frequency values and timing of the most intense events) and propose a palaeo-hydrological reconstruction back to the 14th century from lake sediments in the french mediterranean Alps. Studying a lake sequence in the same region, Wilhelm et al. (2016) highlighted a tendency towards higher frequencies of high-intensity flood events during the warm Medieval Climate Anomaly: consequently, they suggest a possible increase in the intensity of floods in this area under global warming.

Enhancing interactions and communication between hydrological, climatological and palaeo-climatological scientific communities appears more than ever essential to address such crucial issues as understanding the long-term variability of hydro-climatic processes and interpreting current variability and changes under natural climate and anthropogenic forcing.

\section{Conclusion}

This paper presented a summary of some recently used approaches to characterize and understand large-scale hydrological variability, partly based on research conducted by members of EURO-FRIEND Water project 3 "Large-scale- variations in hydrological characteristics". The paper highlighted some key-elements for hydrological variability assessment, understanding and prediction, including the analysis of the climate drivers and multi-time-scales characteristics of hydrological variations. As emphasized throughout this article, the concept of "large-scale variations" must be here understood from both spatial and temporal standpoints. Both dimensions are closely linked: low-frequency hydrological variations can be intuitively associated with homogeneous hydrological behaviors across large areas. In other words, long-term, slow and highly-inertial climate variability logically tends to affect vast regions. This constitutes the basis for hydrological classification, and a supporting principle of many approaches used in hydrology (e.g. double-mass analysis for data homogeneity assessment).

However, this article also underlines that from both spatial and temporal sides, the need appears for bridging the gap between the small and the large scales. Fine-scale hydrologic or hydrogeologic processes are generally well understood, but large-scale hydrological models very often suffer from too simplified representations of the physical characteristics of the basins, which may impair their ability to generate consistent enough hydrological responses to tackle water management challenges under climate change, for instance. Efforts should then continue on the assessment of the way physical properties modulate the climate signal to release hydrological variability on the basin scale. Similarly, from the temporal side, comparison of historical measurements of hydro-climatic variables with (palaeo-)hydroclimatic reconstructions back to the past centuries or millenia (e.g. as elaborated by Pages $2 \mathrm{k}$ groups) seems necessary to improve understanding and interpretation of the long-term variability (of both averages and extremes) as recorded in historical direct measurements of hydro-climatic variables. In this sense, enhancing interactions between hydrological and palaeo-hydrological/palaeo-climatic communities appears fundamental.

Data availability. No data sets were used in this article.

Author contributions. This article was based on a joint reflection/discussion of all authors. Each author was involved in the setting up of the outline, was more particularly in charge of specific sections according to their main field of expertise, and eventually reviewed the final version.

Competing interests. The authors declare that they have no conflict of interest.

Special issue statement. This article is part of the special issue "Hydrological processes and water security in a changing world". 
It is a result of the 8th Global FRIEND-Water Conference: Hydrological Processes and Water Security in a Changing World, Beijing, China, 6-9 November 2018.

Acknowledgements. This paper forms a contribution to the UNESCO-IHP EURO FRIEND-Water programme.

Financial support. Andreas Hartmann has been supported by the Emmy Noether-Programme of the German Research Foundation (DFG; grant no. HA 8113/1-1).

\section{References}

Anctil, F. and Coulibaly, P.: Wavelet analysis of the interannual variability in Southern Québec Streamflow, J. Climate, 17, 163-173, 2004.

Ault, T. R., Cole, J. E., and St. George, S.: The amplitude of decadal to multidecadal variability in precipitation simulated by state-of-the-art climate models, Geophys. Res. Lett., 39, L21705, https://doi.org/10.1029/2012GL053424, 2012.

Ault, T. R., Deser, C., Newman, M., and Emile-Geay, J.: Characterizing decadal to centennial variability in the equatorial Pacific during the last millennium, Geophys. Res. Lett., 40, 3450-3456, 2013.

Bass, A. M., Munksgaard, N. C., O’Grady, D., Williams, M. J. M., Bostock, H. C., Rintoul, S. R., and Bird, M. I.: Continuous shipboard measurements of oceanic $\delta^{18} \mathrm{O}, \delta \mathrm{D}$ and $\delta^{13} \mathrm{CDIC}$ along a transect from New Zealand to Antarctica using cavity ring-down isotope spectrometry, J. Marine Syst., 137, 21-27, 2014.

Boé, J. and Habets, F.: Multi-decadal river flow variations in France, Hydrol. Earth Syst. Sci., 18, 691-708, https://doi.org/10.5194/hess-18-691-2014, 2014.

Caillouet, L., Vidal, J.-P., Sauquet, E., and Graff, B.: Probabilistic precipitation and temperature downscaling of the Twentieth Century Reanalysis over France, Clim. Past, 12, 635-662, https://doi.org/10.5194/cp-12-635-2016, 2016.

Caillouet, L., Vidal, J.-P., Sauquet, E., Devers, A., and Graff, B.: Ensemble reconstruction of spatio-temporal extreme low-flow events in France since 1871, Hydrol. Earth Syst. Sci., 21, 29232951, https://doi.org/10.5194/hess-21-2923-2017, 2017.

Compo, G. P., Whitaker, J. S., Sardeshmukh, P. D., Matsui, N., Allan, R. J., Yin, X., Gleason, B. E., Vose, R. S., Rutledge, G., Bessemoulin, P., Brönnimann, S., Brunet, M., Crouthamel, R. I., Grant, A. N., Groisman, P. Y., Jones, P. D., Kruk, M. C., Kruger, A. C., Marshall, G. J., Maugeri, M., Mok, H. Y., Nordli, Ross, T. F., Trigo, R. M., Wang, X. L., Woodruff, S. D., and Worley, S. J.: The Twentieth Century Reanalysis Project, Q. J. Roy. Meteor. Soc., 137, 1-28, https://doi.org/10.1002/qj.776, 2011.

Coulibaly, P. and Burn, D.: Wavelet analysis of variability in annual Canadian streamflows, Water Resour. Res., 40, W03105, https://doi.org/10.1029/2003WR002667, 2004.

Dayon, G., Boé, J., and Martin, E.: Transferability in the future climate of a statistical downscaling method for precipitation in France, J. Geophys. Res., 120, 1023-1043, https://doi.org/10.1002/2014JD022236, 2015.
Deser, C., Phillips, A., Bourdette, V., and Teng, H.: Uncertainty in climate change projections: the role of internal variability, Clim. Dynam., 38, 527-546, https://doi.org/10.1007/s00382010-0977-x, 2012.

Deser, C., Phillips, A. S., Alexander, M. A., and Smoliak, B. V.: Projecting North American climate over the next 50 years: uncertainty due to internal variability, J. Climate, 27, 2271-2296, https://doi.org/10.1175/JCLI-D-13-00451.1, 2014.

Dieppois, B., Durand, A., Fournier, M., and Massei, N.: Links between multidecadal and interdecadal climatic oscillations in the North Atlantic and regional climate variability of northern France and England since the 17th, J. Geophys. Res.-Atmos., 118, 43594372, 2013.

Dieppois, B., Lawler, D. M., Slonosky, V., Massei, N., Bigot, S., Fournier, M., and Durand, A.: Multidecadal climate variability over northern France during the past 500 years and its relation to large-scale atmospheric circulation, Int. J. Climatol., 36, 46794696, https://doi.org/10.1002/joc.4660, 2016.

El Janyani, S., Massei, N., Dupont, J.-P., Fournier, M., and Dörfliger, N.: Hydrological responses of the chalk aquifer to the regional climatic signal, J. Hydrol., 464, 485-493, 2012.

Fiorella, R. P., Poulsen, C. J., and Matheny, A. M.: Seasonal patterns of water cycling in a deep, continental mountain valley inferred from stable water vapor isotopes, J. Geophys. Res.-Atmos., 123, 7271-7291, https://doi.org/10.1029/2017JD028093, 2018.

Fleig, A. K., Tallaksen, L. M., Hisdal, H., and Hannah, D. M.: Regional hydrological drought in north-western Europe: linking a new Regional Drought Area Index with weather types, Hydrol. Process., 25, 1163-1179, https://doi.org/10.1002/hyp.7644, 2011.

Fritier, N., Massei, N., Laignel, B., Durand, A., Dieppois, B., and Deloffre, J.: Links between NAO fluctuations and inter-annual variability of winter-months precipitation in the Seine River watershed (north-western France), C. R. Geosci., 344, 396-405, 2012.

Giuntoli, I., Renard, B., Vidal, J.-P., and Bard, A.: Low flows in France and their relationship to large-scale climate indices, J. Hydrol., 482, 105-118, 2013.

Gudmundsson, L., Tallaksen, L. M., Stahl, K., and Fleig, A. K.: Low-frequency variability of European runoff, Hydrol. Earth Syst. Sci., 15, 2853-2869, https://doi.org/10.5194/hess-15-28532011, 2011.

Hannaford, J., Buys, G., Stahl, K., and Tallaksen, L. M.: The influence of decadal-scale variability on trends in long European streamflow records, Hydrol. Earth Syst. Sci., 17, 2717-2733, https://doi.org/10.5194/hess-17-2717-2013, 2013.

Hannah, D. M., Fleig, A. K., Kingston, D. G., Stagge, J. H., and Wilson, D.: Connecting streamflow and atmospheric conditions in Europe: state-of-the-art review and future direction, in: Hydrology in a Changing World: Environmental and Human Dimensions, Proceedings of FRIEND-Water 2014, 7-10 October 2014, Montpellier, France, IAHS Publ., 363, 401-406, 2014.

Hartmann, A., Gleeson, T., Wada, Y., and Wagener, T.: Enhanced groundwater recharge rates and altered recharge sensitivity to climate variability through subsurface heterogeneity, P. Natl. Acad. Sci. USA, 114, 201614941, 10.1073/pnas.1614941114, 2017.

Hawkins, E. and Sutton, R.: The potential to Narrow Uncertainty in Regional Climate Predictions, B. Am. Meteorol. Soc., 90, 10951108, 2009. 
Hilmer, M. and Jung, T.: Evidence for a recent change in the link between the North Atlantic Oscillation and Arctic Sea ice export, Geophys. Res. Lett., 27, 989-992, https://doi.org/10.1029/1999GL010944, 2000.

Holman, I. P., Rivas-Casado, M., Bloomfield, J. P., and Gurdak, J. J.: Identifying nonstationary groundwater level response to north Atlantic ocean-atmosphere teleconnection patterns using wavelet coherence, Hydrogeol. J., 19, 1269-1278, 2011.

Iliopoulou, T., Papalexiou, S. M., Markonis, Y., and Koutsoyiannis, D.: Revisiting long-range dependence in annual precipitation, J. Hydrol., 556, 891-900, https://doi.org/10.1016/j.jhydrol.2016.04.015, 2018.

Ionita, M., Tallaksen, L. M., Kingston, D. G., Stagge, J. H., Laaha, G., Van Lanen, H. A. J., Scholz, P., Chelcea, S. M., and Haslinger, K.: The European 2015 drought from a climatological perspective, Hydrol. Earth Syst. Sci., 21, 1397-1419, https://doi.org/10.5194/hess-21-1397-2017, 2017.

James, P. M.: An objective classification method for Hess and Brezowsky Grosswetterlagen over Europe, Theor. Appl. Climatol., 88, 17-42, 2007.

Keenlyside, N. S., Latif, M., Jungclaus, J., Kornblueh, L., and Roeckner, E.: Advancing decadal-scale climate prediction in the North Atlantic sector, Nature, 453, 84-88, 2008.

Kidson, J. W.: An analysis of New Zealand synoptic types and their use in defining weather regimes, Int. J. Climatol., 20, 299-316, 2000.

Kingston, D. G. and McMecking, J.: Precipitation delivery trajectories associated with extreme river flow for the Waitaki River, New Zealand, Proc. IAHS, 369, 19-24, https://doi.org/10.5194/piahs-369-19-2015, 2015.

Kingston, D. G., Fleig, A. K., Tallaksen, L. M., and Hannah, D. M.: Ocean-atmosphere forcing of summer streamflow drought in Great Britain, J. Hydrometeorol., 14, 331-344, https://doi.org/10.1175/JHM-D-11-0100.1, 2013.

Kingston, D. G., Stagge, J. H., Tallaksen, L. M., and Hannah, D. M.: European-scale drought: Understanding connections between atmospheric circulation and meteorological drought indices, J. Climate, 28, 505-516, https://doi.org/10.1175/JCLI-D-14-00001.1, 2015.

Kingston, D. G., Webster, C. S., and Sirguey, P.: Atmospheric circulation drivers of lake inflow for the Waitaki River, New Zealand, Int. J. Climatol., 36, 1102-1113, https://doi.org/10.1002/joc.4405, 2016a.

Kingston, D. G, Lavers, D. A., and Hannah, D. M.: Floods in the Southern Alps of New Zealand: The importance of atmospheric rivers, Hydrol. Process., 30, 5063-5070, https://doi.org/10.1002/hyp.10982, 2016b.

Kuentz, A., Mathevet, T., Coeur, D., Perret, C., Gailhard, J., Guérin, L., Gash, Y., and Andréassian, V.: Historical hydrometry and hydrology of the Durance river watershed, Houille Blanche, 5, 5763, https://doi.org/10.1051/lhb/2014039, 2014.

Kuentz, A., Mathevet, T., Gailhard, J., and Hingray, B.: Building long-term and high spatio-temporal resolution precipitation and air temperature reanalyses by mixing local observations and global atmospheric reanalyses: the ANATEM model, Hydrol. Earth Syst. Sci., 19, 2717-2736, https://doi.org/10.5194/hess-192717-2015, 2015.

Labat, D.: Oscillations in land surface hydrological cycle, Earth Planet. Sc. Lett., 242, 143-154, 2006.
Laizé, C. and Hannah, D. M.: Modification of climate-river flow associations by basin properties, J. Hydrol., 389, 186-204, https://doi.org/10.1016/j.jhydrol.2010.05.048, 2010.

Laloyaux, P., de Boisseson, E., Balmaseda, M., Bidlot, J.-R., Broennimann, S., Buizza, R., Dalhgren, P., Dee, D., Haimberger, L., Hersbach, H., Kosaka, Y., Martin, M., Poli, P., Rayner, N., Rustemeier, E., and Schepers, D.: CERA-20C: A Coupled Reanalysis of the Twentieth Century, J. Adv. Model. Earth Syst., 10, 11721195, https://doi.org/10.1029/2018MS001273, 2018.

Lamb, H. H.: British Isles Weather Types and a Register of Daily Sequence of Circulation Patterns, 1861-1971, Geophysical Memoire 116, HMSO, London, UK, 85 pp., 1972.

Lavers, D. A. and Villarini, G.: The nexus between atmospheric rivers and extreme precipitation across Europe, Geophys. Res. Lett., 40, 3259-3264, 2013.

Lavers, D. A., Prudhomme, C., and Hannah, D. M.: European precipitation connections with large-scale mean sea level pressure (MSLP) fields, Hydrolog. Sci. J., 58, 1-18, 2013.

Lavers, D. A., Pappenberger, F., and Zsoter, E.: Extending mediumrange predictability of extreme hydrological events in Europe, Nat. Commun., 5, 5382, https://doi.org/10.1038/ncomms6382, 2014.

Lavers, D. A., Hannah, D. M., and Bradley, C.: Linking variations in groundwater level in southern England to large-scale atmospheric circulation, J. Hydrol., 523, 179-189, 2015.

Markonis, Y. and Koutsoyiannis, D.: Scale-dependence of persistence in precipitation records, Nat. Clim. Chang., 6, 399-401, 2016.

Markonis, Y., Hanel, M., Maca, P., Kysely, J., and Cook, E. R.: Persistent multi-scale fluctuations shift European hydroclimate to its millennial boundaries, Nat. Commun., 9, 1767, https://doi.org/10.1038/s41467-018-04207-7, 2018.

Massei, N. and Fournier, M.: Assessing the expression of largescale climatic fluctuations in the hydrological variability of daily Seine river flow (France) between 1950 and 2008 using HilbertHuang Transform, J. Hydrol., 448-449, 119-128, 2012.

Massei, N., Laignel, B., Deloffre, J., Mesquita, J., Motelay, A., Lafite, R., and Durand, A.: Long-term hydrological changes of the Seine River flow (France) and their relation to the North Atlantic Oscillation over the period 1950-2008, Int. J. Climatol., 30, 2146-2154, 2010.

Massei, N., Dieppois, B., Hannah, D. M., Lavers, D. A., Fossa, M., Laignel, B., and Debret, M.: Multi-time-scale hydroclimate dynamics of a regional watershed and links to large-scale atmospheric circulation: Application to the Seine river catchment, France, J. Hydrol., 546, 262-275, https://doi.org/10.1016/j.jhydrol.2017.01.008, 2017.

McCabe, G. J. and Wolock, D. M.: A step increase in streamflow in the conterminous United States, Geophys. Res. Lett., 29, 2185, https://doi.org/10.1029/2002GL015999, 2002.

Meehl, G. A., Hu, A., Santer, B. D., and Xie, S.-P.: Contribution of the Interdecadal Pacific Oscillation to twentieth-century global surface temperature trends, Nat. Clim. Chang., 6, 1005-1008, 2016.

Miles, M. W., Divine, D. V., Furevik, T., Jansen, E., Moros, M., and Ogilvie, A. E. J.: A signal of persistent Atlantic multidecadal variability in Arctic sea ice, Geophys. Res. Lett., 41, 463-469, https://doi.org/10.1002/2013GL058084, 2014. 
Minvielle, M., Pagé, C., Céron, J.-P., and Besson, F.: Extension of the SIM Reanalysis by combination of observations and statistical downscaling, in: Engineering Geology for Society and Territory, eidtd by: Lollino, G., Manconi, A., Clague, J., Shan, W., and Chiarle, M., 1, 189-192, https://doi.org/10.1007/978-3-31909300-0_36, 2015.

Pagano, T. and Garen, D.: A recent increase in western U.S. streamflow variability and persistence, J. Hydrometeorol., 6, 173-179, 2005.

Paltan, H., Waliser, D., Lim, W. H., Guan, B., Yamazaki, D., Pant, R., and Dadson, S.: Global floods and water availability driven by atmospheric rivers, Geophys. Res. Lett., 44, 10387-10395, https://doi.org/10.1002/2017GL074882, 2017.

Poli, P., Hersbach, H., Dee, D. P., Berrisford, P., Simmons, A. J., Vitart, F., Laloyaux, P., Tan, D. G. H., Peubey, C., Thépaut, J.-N., Trémolet, Y., Hólm, E. V., Bonavita, M., Isaksen, L., and Fisher, M.: ERA-20C: An atmospheric reanalysis of the twentieth century, J. Climate, 29, 4083-4097, https://doi.org/10.1175/JCLI-D15-0556.1, 2016.

Roberts, C. D., Palmer, M. D., McNeall, D., and Collins M.: Quantifying the likelihood of a continued hiatus in global warming, Nat. Clim. Chang., 5, 337-342, 2015.

Sahin, S., Turkes, M., Wang, S. H., Hannah, D. M., and Eastwood, W. J.: Large scale moisture flux characteristics of the Mediterranean basin and their relationships with drier and wetter climate conditions, Clim. Dynam., 45, 3381-3401, 2015.
Slimani, S., Massei, N., Mesquita, J., Valdés, D., Fournier, M., Laignel, B., and Dupont, J.-P.: Combined climatic and geological forcings on the spatio-temporal variability of piezometric levels in the chalk aquifer of Upper Normandy (France) at pluridecennal scale, Hydrogeol. J., 17, 1823-1832, 2009.

Stahl, K., Hisdal, H., Hannaford, J., Tallaksen, L. M., van Lanen, H. A. J., Sauquet, E., Demuth, S., Fendekova, M., and Jódar, J.: Streamflow trends in Europe: evidence from a dataset of nearnatural catchments, Hydrol. Earth Syst. Sci., 14, 2367-2382, https://doi.org/10.5194/hess-14-2367-2010, 2010.

Thiéry, D., Amraoui, N., and Noyer, M.-L.: Modelling flow and heat transfer through unsaturated chalk - Validation with experimental data from the ground surface to the aquifer, J. Hydrol., 556, 660-673, 2018.

Wilhelm, B., Sabatier, P., and Arnaud, F.: Is a regional flood signal reproducible from lake sediments?, Sedimentology, 62, 11031117, https://doi.org/10.1111/sed.12180, 2015.

Wilhelm, B., Vogel, H., Crouzet, C., Etienne, D., and Anselmetti, F. S.: Frequency and intensity of palaeofloods at the interface of Atlantic and Mediterranean climate domains, Clim. Past, 12, 299-316, https://doi.org/10.5194/cp-12-299-2016, 2016.

Zhang, R., Delworth, T. L., and Held, I. M.: Can the Atlantic Ocean drive the observed multidecadal variability in Northern Hemisphere mean temperature?, Geophys. Res. Lett., 34, L02709, https://doi.org/10.1029/2006GL028683, 2007. 